\title{
Impact of the Physical Web and BLE Beacons
}

\author{
Debasis Bhattacharya, JD, DBA \\ University of Hawaii Maui College \\ HI 96732 \\ debasisb@ hawaii.edu
}

\author{
University of Hawaii Maui College \\ Mario Canul \\ 310 W. Kaahumanu Avenue, Kahului \\ HI 96732 \\ mcanul@hawaii.edu
}

\author{
Saxon Knight \\ University of Hawaii Maui College \\ 310 W. Kaahumanu Avenue, Kahului \\ HI 96732 \\ knight7@hawaii.edu
}

\begin{abstract}
The Physical Web is a project announced by Google's Chrome team that essentially provides a framework to discover "smart" physical objects (e.g. vending machines, classroom, conference room, cafeteria etc.) and interact with specific, contextual content without having to resort to downloading a specific app. A common app such as the open source and freely available Physical Web app on the Google Play Store or the BKON Browser on the Apple App Store, can access nearby beacons.
\end{abstract}

A current work-in-progress at the University of Maui College is developing a campus-wide prototype of beacon technology using Eddystone-URL and EID protocol from various beacon vendors.

\section{Keywords}

Cybersecurity; computer security; beacons; Bluetooth; BLE; Physical Web; Eddystone; Eddystone-URL; iBeacon.

\section{INTRODUCTION}

A beacon is a low-cost hardware that transmits a short burst of data over a small distance using the Bluetooth Low Energy (BLE) protocol [3]. This data contains basic text information that could include a URL and other relevant information. Any smartphone that supports the BLE protocol and pick up this data signal and present the information to the user. As a result of this interaction, a user can receive contextual information from beacons as they come within its proximity or range.

\section{BACKGROUND}

Beacons were first introduced by Apple in 2013 at the Apple Worldwide Developers Conference. Using the iBeacon protocol, Apple demonstrated beacons that transmitted a small unique id from a transmitter to a receiver which could be an Apple iPhone. These simple devices provided a unique ID and description from the beacon and alerted iPhone and other users with information when they were within range.

In response to the offering from Apple, Google released their open specification of the Eddystone BLE beacon protocol in July 2015 [3]. The entire specification is available at GitHub (see https://github.com/google/eddystone) and is freely available to all. The early specification of Eddystone was similar to iBeacon and focused on smartphones that supported the Android OS.

Permission to make digital or hard copies of part or all of this work for personal or classroom use is granted without fee provided that copies are not made or distributed for profit or commercial advantage and that copies bear this notice and the full citation on the first page. Copyrights for thirdparty components of this work must be honored. For all other uses, contact the Owner/Author. Copyright is held by the owner/author(s). RIIT'16, September 28 - October 1, 2016, Boston, MA, USA.

ACM 978-1-4503-4453-1/16/09.

DOI: http://dx.doi.org/10.1145/2978178.2978179

\section{BEACONS AND SECURITY}

The initial beacon protocols (iBeacon and Eddystone) from Apple and Google did not focus on security and privacy issues and concerns [3]. The BLE protocol also did not consider security and privacy issues and the usage of BLE with insecure beacons, essentially opened up the implementation to exploits. With the emerging popularity of BLE beacons with retailers, hospitals, stadiums, educational institutions and other businesses, there were specific instances of security and privacy that were becoming too glaring to ignore.

A key paper by Google [1] identified the security issues and concerns with the current Eddystone and iBeacon technology. The authors described the key concerns and provided a new protocol called the Eddystone Ephemeral ID (EID) as a proposal solution.

\section{CASE STUDY}

Given the above issues and concerns with BLE beacons, it is conceivable that an implementation within an educational institution comes with risks and concerns. As a result, the case study at the University of Hawaii Maui College (UHMC) demonstrates the use of BLE Beacons from various vendors such as Estimote, Accent, Radius Technologies and BKON. The use of Eddystone EID [2] allows for registered users to access specific beacons, assuming they are authorized to do so. If a user approaches a beacon that he/she is not authorized to access, the user does not see the beacon at all. As a result, the Ephemeral ID, based on registration of the beacon with a "global resolver", allows only registered users to access specific beacons [2].

\section{CONCLUSION}

BLE beacons are an emerging technology and have recently been deployed in various physical locations such as educational institutions. The Physical Web is a collection of locations, objects and things that are marked with a BLE beacon that can provide users in close physical proximity with latest information and updates. Given that many users use their smartphones to navigate the physical world around us, this physical web of beacons can provide with contextual information as users move from one place to another.

\section{REFERENCES}

[1] Avinatan Hassidim et al. "Ephemeral Identifiers: Mitigating Tracking \& Spoofing Threats BLE Beacons". url: https://developers.google.com/beacons/eddystone-eidpreprint.pdf.

[2] Eddystone-EID. url: https://developers.google.com/beacons/eddystone-eid

[3] Proximity Beacon API Overview. url: https://developers.google.com/beacons/proximity/guides 